\title{
Stationarity of maximum low-flow periods duration in the right-bank area of the Upper Vistula catchment - Mann-Kendall versus Spearman test
}

\author{
Katarzyna Baran-Gurgul ${ }^{1, *}$ \\ ${ }^{1}$ Cracow University of Technology, Institute of Water Engineering and Water Management, \\ ul. Warszawska 24, 31-155 Kraków, Poland
}

\begin{abstract}
This study compares two methods of analyzing the stationarity of time series - the Spearman test and the Mann-Kendall test, with the formula adjusted by Hamed and Rao. Daily discharge series collected at 78 gauging stations were compared for a period of 30 years. The study area consisted of the right-bank area of the Upper Vistula River catchment. Low-flow periods were identified via the pit under threshold method (PUT). Threshold discharge values in the study were represented by $Q_{70 \%}$, $Q_{80 \%}$, and $Q_{90 \%}$. Maximum annual durations $T_{\max , i},(i=1,2, \ldots, 30$ lowflow periods) were identified for assumed threshold discharge values based on low-flow period duration series for selected gauging stations. Research on the stationarity of $T_{\max R}$ series for most of the studied water gauging stations has shown an absence of a basis for the rejection of the hypothesis of a lack of a trend for peak low-flow period duration relative to time, independently of assumed threshold discharge. Most of the detected trends are decreasing trends. The lower the threshold discharge value, the larger the number of $T_{\max R}$ series being non-stationary. The Spearman test detected more non-stationary series than the Mann-Kendall test for the studied gauging stations, independently of assumed threshold discharge values.
\end{abstract}

\section{Introduction}

The evaluation of seasonal and multi-annual variability of river discharge, including variability of the occurrence and characteristics of low-flow periods, is one of the most important themes in modern hydrology. Multi-annual variability of discharge time series, including periods of low flow, has been analyzed in a large number of papers. Trend analyses included a number of different tests including non-parametric tests such as the Mann-Kendall test and the rank correlation test by Spearman [1-7]. Work by Yue et al. [8] has shown that these two tests are almost equally powerful in the identification of trends in time series.

* Corresponding author: Katarzyna.Baran-Gurgul@iigw.pk.edu.pl 
A low-flow event represents a process of continuous water discharge at a given gauging station below an assumed threshold level [9-13]. For the pit under threshold method (PUT) [14], the onset $t_{p}$ of a low-flow period occurs at the moment when discharge decreases below a threshold value $Q_{g}$ and the end $t_{k}$ of a low-flow period occurs when discharge once again exceeds the value $Q_{g}$. The low-flow duration $t_{n}$ is measured in 24-hour periods in the form: $t_{n}=t_{k}-t_{p}+1$. In order to eliminate short durations with discharge less than $Q_{g}$ that are considered irrelevant from the perspective of water shortages, the following assumption is also employed: minimum low-flow duration $t_{\min }$. In the research literature, this value ranges broadly from 5 days to 21 days $[9,15-19]$. If two adjacent low-flow periods are separated by a few days when discharge is greater than the threshold value $Q_{g}$, then one may consider these periods to be dependent in order to combine them into a longer time period. In most cases, durations for each low-flow period are added together [10, 15-19].

In this paper, a maximum annual low-flow period is defined as a low-flow period with a longest duration over the course of the hydrologic year. If a low-flow period starts during one year and ends during another, then it is assigned to the year when its middle happens to occur.

The purpose of the paper is to compare two methods of analyzing the stationarity of time series for maximum low-flow periods measured at 78 water gauging stations in the catchment of the Upper Vistula River in southeastern Poland. The two methods are the rank correlation test by Spearman and the Mann-Kendall test adjusted by Hamed and Rao, which considers the issue of autocorrelation in time series [20].

\section{Materials}

The study is based on daily discharge series for the period from 1.11.1983 to 31.10.2013. This yields a total of 30 hydrologic years and 10,958 discharge values obtained at each of 78 water gauging stations located across the right-bank area of the Upper Vistula River. The data were obtained from the Institute of Meteorology and Water Management National Research Institute (IMWM-NRI). The location of the sites is shown in Fig. 1.

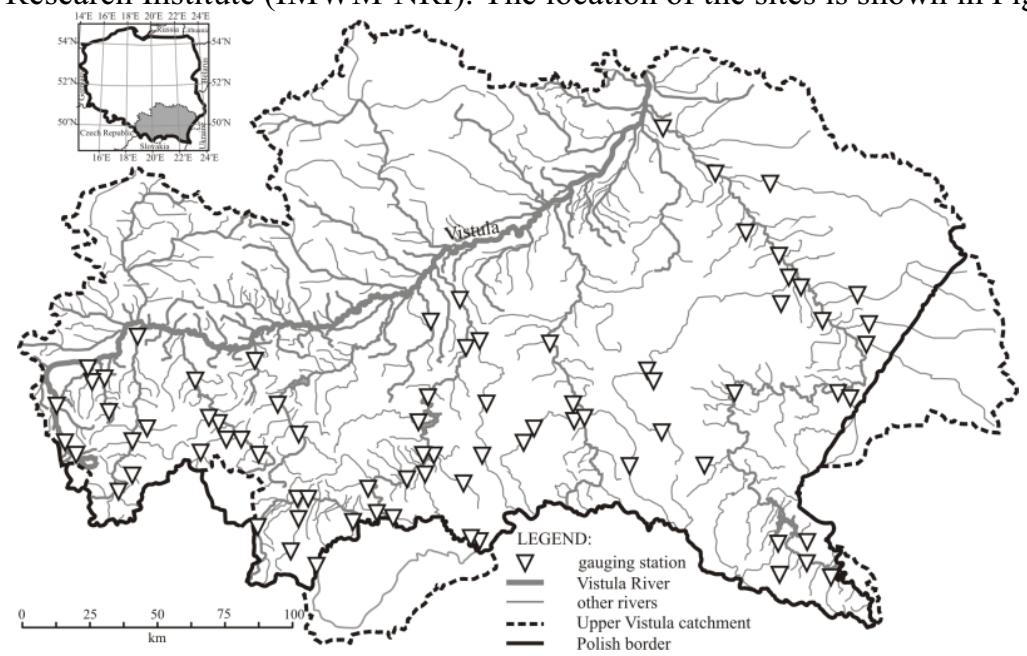

Fig. 1. Location of selected water gauging stations in the catchment of the Upper Vistula.

Most of the rivers in the study (68 of 78) featuring water gauging stations are secondorder and third-order rivers. About half of the studied catchments (42 of 78) have surface areas ranging from 100 to $1,000 \mathrm{~km}^{2}$. Most of the water gauges used in the study are located at sites found below 400 meters above sea level. 
Low-flow periods were identified using the PUT method. Threshold discharge values for this study were assumed to be ones with an exceedance probability of $0.7,0.8$, and 0.9 $\left(Q_{70 \%}, Q_{80 \%}, Q_{90 \%}\right)$, as read from the flow duration curve. It was also assumed that a single low-flow period must last at least 7 days. Furthermore, if the time gap between 2 consecutive low-flow periods was shorter than 4 days, then the two periods were combined into one period.

Maximum durations time series $T_{\max R, i}(i=1,2, \ldots, 30$ maximum annual low-flow periods) were identified for assumed threshold discharge values based on a series of lowflow period durations observed at selected water gauging stations in the study area.

The maximum mean duration $\overline{T_{\max R}}$ for low-flow periods based on data obtained at all the water gauging stations - and independently of assumed threshold discharge values were noted for the years 1987, 1994, 2003, and 2012 (Fig. 2). The longest low-flow durations or those over 200 days occurred with threshold discharge at $Q_{70 \%}$ (Fig. 3) in the years 1984 (gauge no. 10), 1993 (gauges no. 5, 6), and 2003 (gauges no. 7, 20, 47).

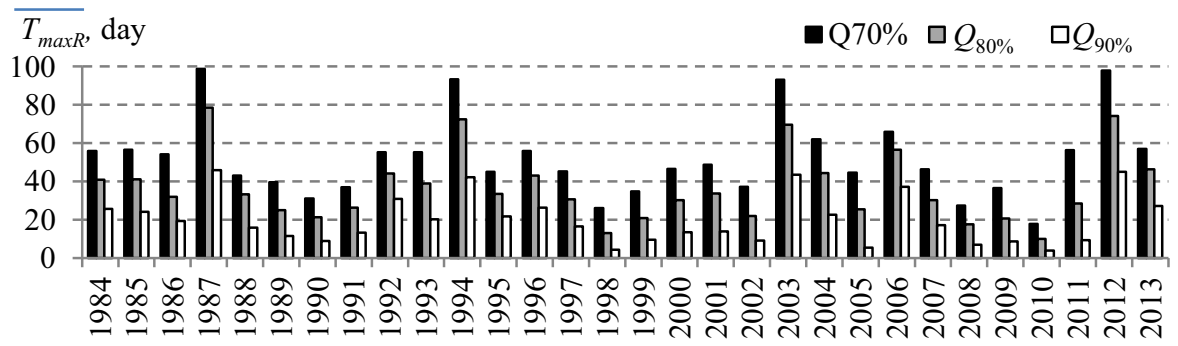

Fig. 2. Mean durations $\overline{T_{\max R}}$ for annual low-flow periods, in the study period, at 78 water gauging stations in the Upper Vistula catchment varying with assumed threshold discharge.

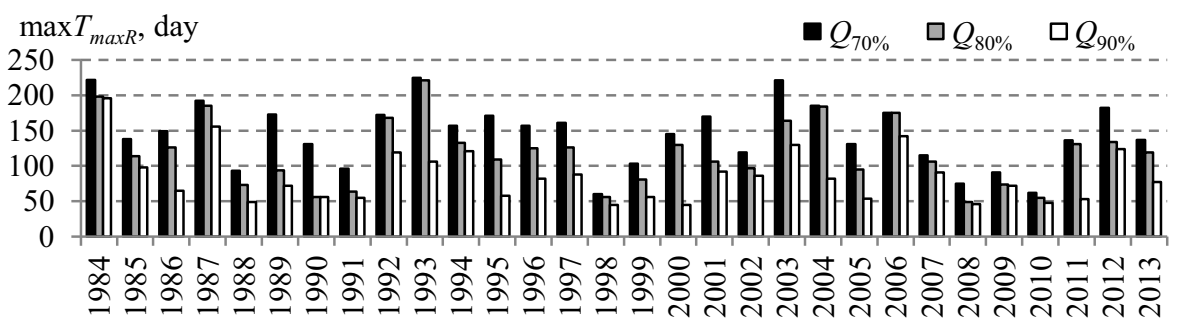

Fig. 3. Maximum durations $\max T_{\max R}$ for annual low-flow periods, in the study period, at 78 water gauging stations in the Upper Vistula catchment varying with assumed threshold discharge.

\section{Methods}

Trend analysis was performed via both the Mann-Kendall and Spearman tests for every time series for maximum low-flow periods $T_{\max , i}, i=1,2, \ldots, 30$. Both tests are nonparametric, and are designed to verify hypothesis $\mathrm{H}_{0}$ on the absence of a trend in a time series $T_{\max , i}$, and more precisely that variables $T_{\max , i}$ are independent and feature identical distributions, with an alternative hypothesis $\mathrm{H}_{1}$ on the presence of a monotonic trend in time series $T_{\max , i}$.

\subsection{The Mann-Kendall trend test}

What is given is a time series $X_{i}, i=1,2, \ldots, n$. The test statistic is defined as $[5,8,11$, 20, 21]: 


$$
S=\sum_{i=1}^{n-1} \sum_{j=i+1}^{n} \operatorname{sgn}\left(x_{j}-x_{i}\right)
$$

where:

$$
\operatorname{sgn}(\theta)=\left\{\begin{array}{cc}
1 & \text { if } \theta>0 \\
0 & \text { if } \theta=0 \\
-1 & \text { if } \theta<0
\end{array}\right.
$$

When $\mathrm{H}_{0}$ is true, the mean and variance of $S$ are given by:

$$
\begin{gathered}
E(S)=0 \\
\operatorname{var}(S)=\frac{n(n-1)(2 n+5)}{18}
\end{gathered}
$$

The above equality (4) occurs when there are no repeated elements of a time series (socalled ties). If there are more than a few repeating elements, then the formula (4) needs to be adjusted, which yields the following form [21]:

$$
\operatorname{var}(S)=\frac{n(n-1)(2 n+5)}{18}-\frac{\sum_{i=1}^{k} t_{i} \cdot i(i-1)(2 i+5)}{18}
$$

where $t_{i}, i=1,2, \ldots, k$, indicates that there exists a number of groups with $k$ repeating elements.

Kendall [22] proved that when $n>10$, then the test statistic:

$$
U=\frac{S-\operatorname{sgn}(S)}{\sqrt{\operatorname{var}(S)}}
$$

approximately follows the standard normal distribution $\mathrm{N}(0 ; 1)$. If the $p_{v}$-value of the hypothesis test is equal to the chosen significance level $(\alpha=5 \%)$, the null hypothesis must be rejected.

The basic assumption when using this test is a lack of autocorrelation in the data series. If this condition is not met and autocorrelation is positive, then the variance $\operatorname{var}(S)$ is underestimated. Bayley and Hammersley [20] introduced a variance adjustment:

$$
\operatorname{var}^{*}(S)=\frac{n}{n_{S}^{*}} \operatorname{var}(S)
$$

when using "an effective number of observations $n_{S}^{*}$," which Hamed and Rao [20] suggest to determine using the following formula:

$$
\frac{n}{n_{S}^{*}}=1+\frac{2}{n(n-1)(n-2)} \sum_{i=1}^{n-1}(n-i)(n-i-1)(n-i-2) \rho_{S}(i)
$$

where $n$ is the number of observations and $\rho_{S}(i)$ is the autocorrelation function for observation ranks. The variance adjustment is only calculated for data whose autocorrelations are significant at 5\% level. 
The variance $\operatorname{var}(S)$ in (6) is replaced by $\operatorname{var}^{*}(S)$ from (7) and the rest of the testing process is the same as in (6) (i.e. comparing the values of $U$ with the quantiles of $\mathrm{N}(0 ; 1)$ corresponding to the type I error of the test).

\subsection{The Spearman trend test}

Let $X_{i}, i=1,2, \ldots, n$, be a time series. The test statistic is defined as $[8,10,11,21,23]$ :

$$
R_{S}=1-\frac{6 \sum_{i=1}^{n}\left[R\left(X_{i}\right)-i\right]^{2}}{n\left(n^{2}-1\right)}
$$

where $R\left(X_{i}\right)$ is the rank of observation $X_{i}$. Repeating values (or ties) are assigned a mean rank.

If $n \geq 10$ [24], then the test statistic

$$
t_{S}=R_{s} \sqrt{\frac{n-2}{1-R_{S}^{2}}}
$$

follows Student's distribution with $n-2$ degrees of freedom.

If the $p_{v}$-value of the hypothesis test is equal to the chosen significance level $(\alpha=5 \%)$, the null hypothesis must be rejected.

\section{Results}

The Mann-Kendall and Spearman tests were used to analyze multi-annual variability trends for time series $T_{\max R, i}(i=1,2, \ldots, 30)$ for low-flow periods, given three threshold values of discharge $\left(Q_{70 \%}, Q_{80 \%}, Q_{90 \%}\right)$ and data from 78 water gauging stations spread across the right bank of the Upper Vistula catchment. The $p_{v}$ values obtained for the hypotheses of both examined tests $\left(p_{v, M K}-\right.$ Mann-Kendall test, $p_{v, S}-$ Spearman test) resemble one another for all the considered cases (Fig. 4).
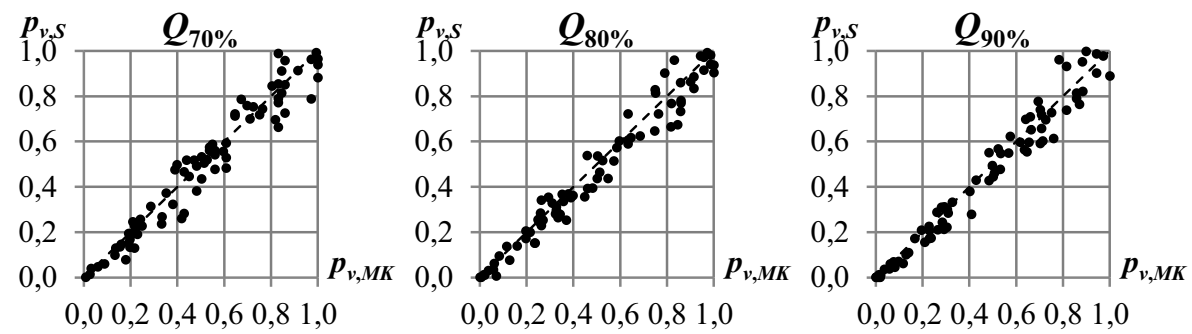

Fig. 4. Relationship between $p_{v, M K}$ values and $p_{v, S}$ obtained from the Mann-Kendall test and the Spearman test, respectively, for threshold discharge $Q_{70 \%}, Q_{80 \%}$ and $Q_{90 \%}$ at 78 water gauging stations in the right-bank area of the Upper Vistula catchment.

Research on the stationarity of $T_{\max R}$ series at most water gauging stations in the study area has shown the lack of a basis for the rejection of the hypothesis on the absence of a trend in the maximum duration $T_{\max R}$ of low-flow periods relative to time, independently of the assumed threshold discharge value. Figure 5 shows only cases where at least one test showed non-stationarity. At the threshold discharge $Q_{70 \%}$ both the $p_{v, M K}$ value of the MannKendall test and the $p_{v, S}$ value of the Spearman test are smaller than the herein assumed level of significance (0.05) in three cases (marked as dots); a trend was indicated only once 
by the Spearman test (marked as asterisk). The lower the threshold discharge, the larger the number of cases where $T_{\max R}$ series are non-stationary; at the threshold discharge $Q_{80 \%}$ both tests showed a trend in five cases, while at $Q_{90 \%}$ the number of cases was 11 . The Spearman test yields a larger number of series characterized by non-stationarity than the MannKendall test for the studied water gauging stations, independently of the assumed threshold discharge value ( $Q_{70 \%}$ : one more case, $Q_{80 \%}$ and $Q_{90 \%}$ : two more cases).
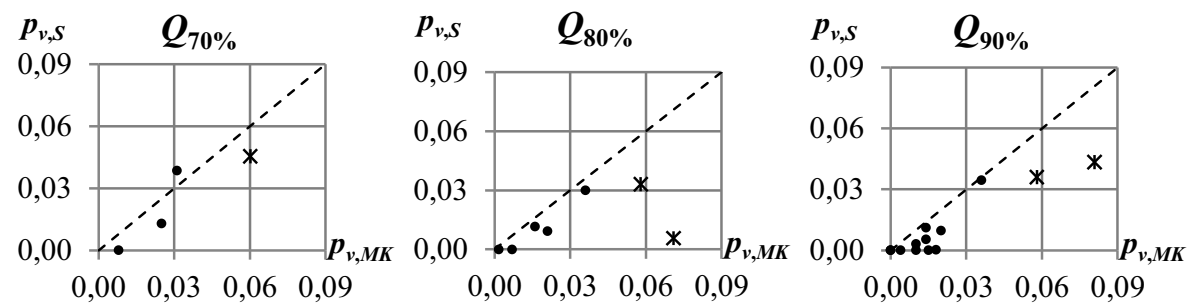

Fig. 5. Relationship between $p_{v, M K}$ values and $p_{v, S}$ obtained from the Mann-Kendall test and the in the Spearman test right-bank area of the Upper Vistula catchment in the special case when $p_{v, M K}<5 \%$ and $p_{v, S}<5 \%$ (dots), $p_{v, M K} \geq 5 \%$ and $p_{v, S}<5 \%$ (asterisks).

Figure 6 shows the spatial distribution of water gauging stations and associated stationarity information for time series for the studied maximum $T_{\max }$ low-flow periods.

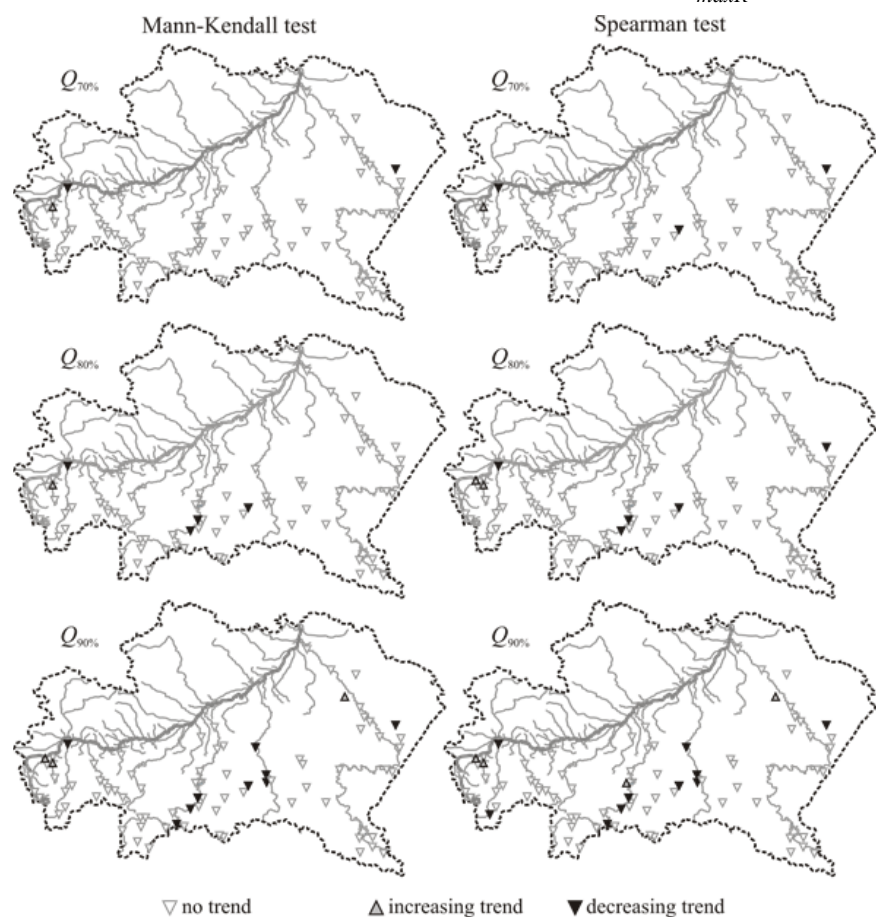

Fig. 6. Location of water gauging stations and information on series stationarity for maximum lowflow periods $T_{\max R}$ with respect to the test employed and the threshold discharge value.

Figure 7 shows the multi-annual $T_{\max R}$ distribution for all cases where at least one of the tests yields a trend for a $T_{\max R}$ series, or more specifically when $p_{v, M K}<5 \%$ and $p_{v, S}<5 \%$ (frameless graphs) and $p_{v, M K} \geq 5 \%$ and $p_{v, S}<5 \%$ (framed graphs). The observed trends are mostly decreasing trends. Both tests indicated the presence of a trend only in the case of the Czechowice-Bestwina station located on the Biała River (gauge no. 7), independently of the assumed threshold discharge value, with the $p_{v}$-value of the hypothesis test at less than $1 \%$. 
In the case of 14 of 78 gauging stations, at least one of the examined tests showed the presence of a trend for a $T_{\max R}$ series for at least one threshold discharge value.
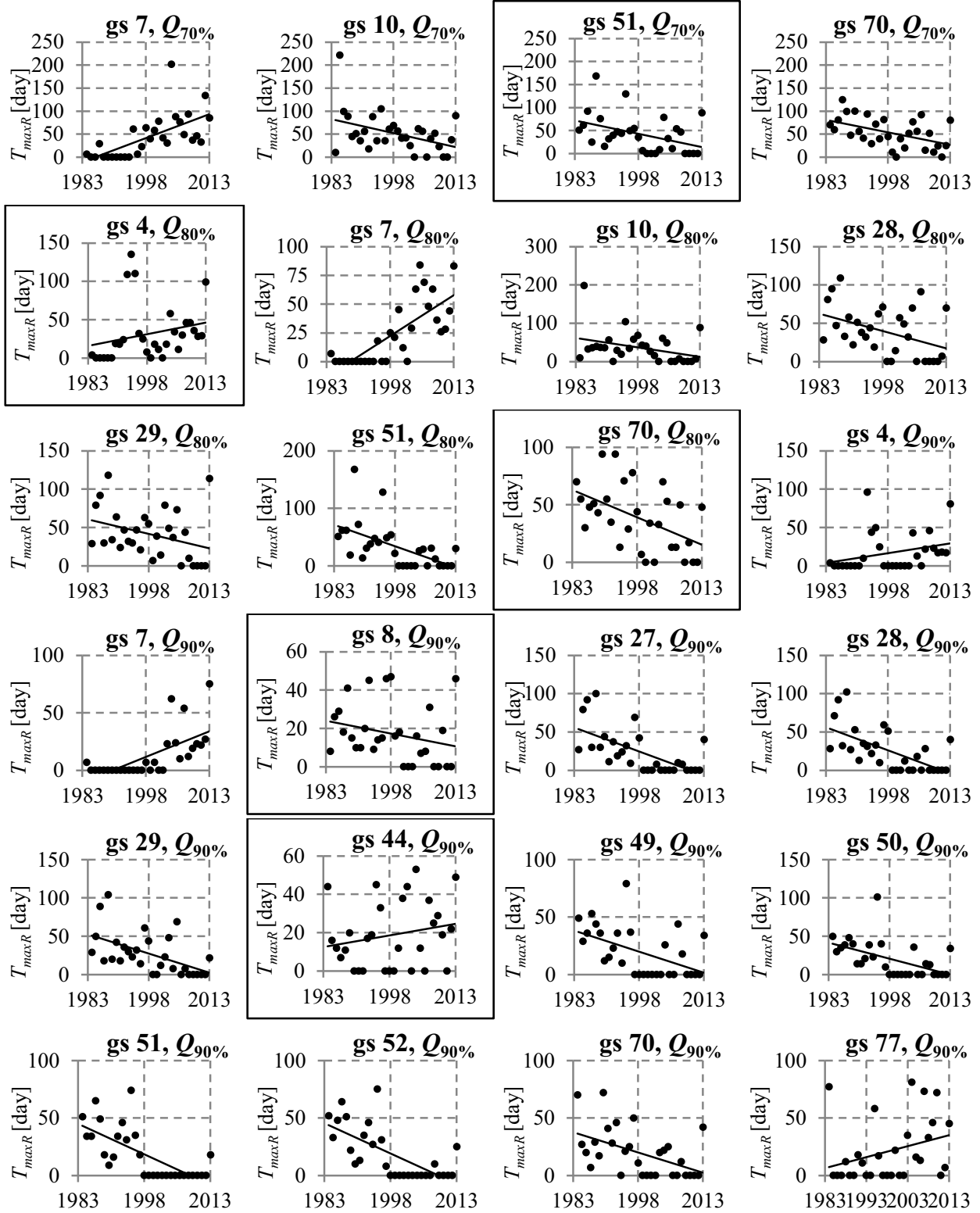

Fig. 7. $T_{\max R}$ values over the long term for cases where at least one of two tests indicated the presence of a trend - frameless graphs: $p_{v, M K}<5 \%$ and $p_{v, S}<5 \%$; framed graphs: $p_{v, M K} \geq 5 \%$ and $p_{v, S}<5 \%$; abbreviation gs 7 denotes river gauging station number 7 . The lines are constructed using OLS method.

\section{Final remarks}

Research on the stationarity of $T_{\max R}$ series - for most water gauging stations - has shown a lack of a basis for the rejection of the hypothesis on the absence of a trend for maximum duration $T_{\max }$ for low-flow periods with respect to time, independently of 
threshold discharge values assumed in the study. In the case of 14 of 78 water gauging stations, at least one of the two tests examined did indicate non-stationarity for at least one threshold discharge value. Most of the trends noted in this study are decreasing trends.

Comparative analysis has shown that the lower the threshold discharge value, the higher the number of cases where $T_{\max }$ series are non-stationary. The Spearman test yields a larger number of series characterized by non-stationarity than the Mann-Kendall test for the studied water gauging stations, independently of the assumed threshold discharge value. The inflation of the variance of the test statistic caused by positive autocorrelation may be the reason. Although the tests are very similar, only the MK test takes into account this autocorrelation. The largest probability of non-stationarity was noted for the CzechowiceBestwina gauging station on the Biała River, with a very low (less than $1 \%$ ) $p_{v}$-value of the null hypothesis.

This study was part of a larger research endeavor: „The influence of anthropogenic factors on qualitative and quantitative properties of hydrological processes in the catchment", task 3: Analysis of low flow properties in the Carpathian area of the Upper Vistula River basin. The data has been provided by the Institute of Meteorology and Water Management, National Research Institute.

\section{References}

1. E. M. Douglas, R. M. Vogel, C. N. Knoll, J. Hydrol., 240, 90-105 (2000)

2. J. Hannaford, T. Marsh, Int. J. Climatol., 26, 1237-1253 (2006)

3. E. Kahya, S. Kalayc1, J. Hydrol., 289, 128-144 (2004)

4. A. Rutkowska, Acta Sci. Pol., Form. Cir., 12 (4), 85-94 (2013)

5. A. Rutkowska, M. Ptak, Stud. Geotech. Mech. 34 (1), 51-63 (2012)

6. C. Svensson, Z.W. Kundzewicz, T. Maurer, Hydrolog. Sci. J., 50 (5), 811-824 (2005)

7. M. Zeleňáková, P. Purcz, T. Soláková, B. Demeterová, Acta U. Agr. Et Silv. Mend. Brun., LX (5), 265-274 (2012)

8. S. Yue, P. Pilon, G. Cavadias, J. Hydrol., 259 (1-4), 254-271 (2002)

9. H. Hisdal, L. M. Tallaksen, Drought Event Definition (Technical Report No. 6, University of Oslo, 2000)

10. M. Ozga-Zielińska, J. Brzeziński, Hydrologia stosowana. (PWN, Warszawa 1997)

11. J. Pociask-Karteczka (ed.), Zlewnia. Właściwości i procesy. (Wyd. UJ, Kraków, 2006)

12. V. U. Smakhtin, J. Hydrol., 240, 147-186 (2001)

13. S. Węglarczyk, Słownik terminów związanych z gospodarowaniem zasobami wodnymi. (Wyd. PK, Kraków, 2006).

14. L. Gottschalk, Y. Kun-xia, E. Leblois, L. Xiong, J. Hydrol., 481, 204-219 (2013)

15. B. Ratomska, Ocena suszy w aspekcie hydrologicznym (Ph.D. Thesis, PK, 1993)

16. E. Zelenhasić, A. Salvai, Water Resou. Res., 23 (1), 156-168 (1987)

17. W. Jakubowski, Rozkłady prawdopodobieństwa $w$ ocenie suszy hydrologicznej. (monogr., UP, Wrocław, 2011)

18. T. Tokarczyk, Acta Geophys, 61 (2), 404-421 (2013)

19. A. K. Fleig, L. M. Tallaksen, H. Hisdal, S. Demuth, S., Hydrol. Earth Syst. Sci. 10 (4), 535-552 (2006)

20. K. H. Hamed, A. R. Rao, J. Hydrol., 204 (1-4), 182-196 (1998)

21. S. Węglarczyk, Statystyka w inżynierii środowiska (Wyd. PK, Kraków, 2010)

22. M. G. Kendall, Biometrika, 30, 81-93 (1938)

23. D. R. Helsel, R. M. Hirsch, Statistical Methods in Water Resources (USGS-TWRI Book 4, Chapter A3, 2002)

24. R. H. McCuen, Modeling Hydrologic Change: Statistical Methods (Lewis Publishes, U. S. CRC Press, 2002) 